\title{
The Localization Style Design Analysis of Domestic Animation The case study of Scissor Seven
}

\author{
Liu Fusong ${ }^{1}$ \\ ${ }^{1}$ Department of Art\&Design Guangzhou Vocational College of Technology \& Business, GuangZhou, Canton, China
}

\begin{abstract}
Scissors Seven as a GuangZhou native animation works has won a large number of fans on the Internet, network playback volume reached 260 million, and in 2018 became the only domestic animation in the Annecy international animation film festival, in 2019, in 2020 Magnolia Award for Best Animated Screenplay at the 26th Shanghai TV Festival became the only domestic animation work award in the past five years.Further more the film became Netflix online products, The Japanese and English versions can be seen in 29 countries and 190 regions .Most of the audiences love this work and gave a good comments.

This paper will analyze the visual and auditory elements of the work around the localized style design of the film, so as to obtain the inspiration and thinking of domestic animation design.
\end{abstract}

\section{Scissor Seven became a hot network animation}

Scissor Seven 2018 has been be shown on the Internet in the form of a domestic animated TV series.(Fanju)(1)As a martial arts style of animation its content is covered in thick Canton local features, blood in the fantasy style of martial arts at the same time, both with warm heart of the plots, the film in the first quarter since its launch in 2018, is widely popular with audiences of different ages, with its unique style of the frame and the content of the unconventional plots quickly accumulated a large number of fans, and in Douban score of 8.9, and 9.8 in Bilibili, in the entire network full channel broadcast scored nearly 1 billion good grades. The second season of The Most Powerful Hairstylist was officially launched on Oct 23, 2019, and the series animation has topped the list of hottest and hottest searches on major video platforms since its issue.

Undoubtedly, this film has withstood the test of the local market and loved by animation lovers at domestic and abroad.

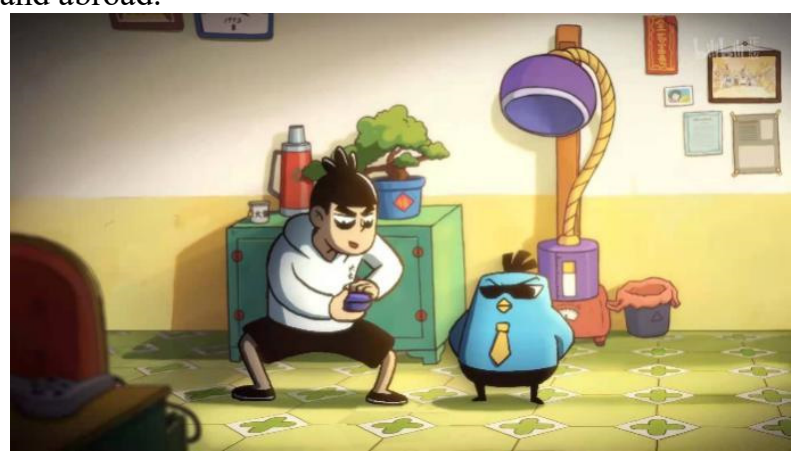

Fig1. Localized interior design in the film
Director He Weifeng, is a native Cantonese graduated from Guangzhou Academy of Fine Arts majoring in animation design in 2010. He has been influenced by the local culture since childhood. He has the natural cultural genes of the local culture of LingNan region. Therefore, his works also naturally make use of the local materials to create.

When He was in college, China's animation industry was not booming, with shoddily produced, plagiarised and juvenile works emerging one after another. Lack of excellent animation works, capital is not willing to enter, the industry can not make money, the animation market once reached an impasse.

"At that time, there was no Internet animation, and the only way to watch cartoons was through a single TV channel. Moreover, the market was mostly relatively young works." He Weifeng recalled.

It is very difficult to stick to create a good work in such an environment. Four years after graduation, Director He also tried to do network animation, but the effect was not very good. After some adjustments, he began to plan new animation projects again. Based on the previous experience, he personally participated in the animation script creation, character design, shooting, dubbing, music and other aspects to control the quality of the works. Finally, he completed the first season series animation of Scissors Seven in 2018. the release soon aroused strong following on the internet. From the process of work creation, the director's comprehensive ability in planning, design, and production is fully demonstrated. The director was able to elevate a local characteristic animation work to a high level of influence at domestic and abroad, demonstrating the pragmatic and enterprising spirit of the new generation of animation directors and animation team. According to online video interviews and personal exchanges, directors are greatly influenced by the culture 
of Japanese films and anime in terms of their international vision. This influence is reflected in the creative ideas of Japanese directors in the 1960s and 1970s, such as Ozu Yasujiro and Akira Kurosawa. He felt that domestic animation or films should be like their work to reflect the local culture and street life, let the audience in the first time to be able to see the obvious regional characteristics and cultural characteristics, it is adhering to such a kind of creation concept guide, the localization style of the Scissor Seven also obviously revealed.

In this paper will analyze the special audio-visual feeling brought to the audience by the localized detailed design of the film from the following aspects.

\section{Analysis of local characters of this animation}

\section{1 animation visual design with local characteristics to increase the sense of inclusion and affinity}

This film draws on real life and local elements in real time, making the film stylized prominent. The audience can see the life details in the real life in the form of interpretation and presentation in the cartoon. It enables the audience to shuttle between the real space, the different dimension space, and the martial arts film space, thus generating the experience of watching films that are both real and unreal, real and virtual.

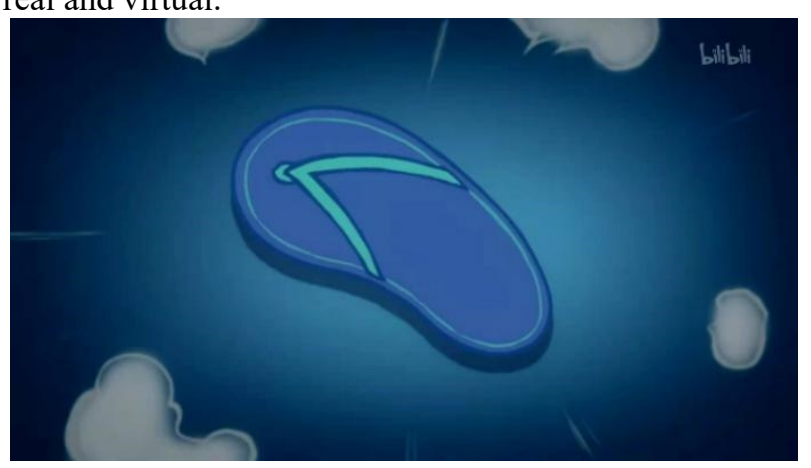

Fig2. Flip-flops are normal wear in Canton

In the opening scene of the film is a logo animation, in which a bird is beaten by a flip-flop, indicating the obvious localized style of the animation. Flip-flops are ordinarily everyday items, due to the Canton the weather is hot and humid, years of flip-flops from Canton are common, flipflops gives the impression of being leisure lazy intuition, the spread of the Internet some of flip-flops and Cantonese stems, such as Cantonese flip-flops to buy luxury cars, buy a person of extraordinary powers curtilage, as a charter male, thus flip-flops, beach pants became a low-key and pragmatic in Canton rich image of curing. The second everyday function of the Cantonese flip-flops is to beat cockroaches, as been use to called in Canton as Xiaoqiang. (Cockroaches are commonly referred to as Xiaoqiang because they are resilient and transmissible. In Canton, a proverb says there is a that cockroach can't be killed, to describe a strong spiritual force, which should be the director's hope for the work.) Therefore, from the point of view of the opening animation design, the film has been filled with a very secular features of Canton.
The animation visual design of the film is full of Cantonese characteristics, including the geographical environment, architecture, food and so on. First of all, the location of the film creation in terms of geographical environment in the pearl river delta, the pearl river delta, near the sea there are many similar production chicken island's geographical environment, the design is the living environment for a long time, such as island, big banyan tree, a small fishing boat wharf, beaches, coastal road, the road corner mirror (young people used to use road corner mirror for selfphoto), sand and so on. These are very everyday ordinary objects and scenes in the local area. The director turned them into the environment of the story and let them appear in the animation. In the eyes of the local audience, such a design can quickly evoke the sense of regional identity and increase the sense of substitution and affinity of the animation. this kind of setting is for the nonlocal audience, the island style animation is generally full of fresh and romantic emotional appeal, which makes people yearn for, thus increasing the curiosity and freshness.

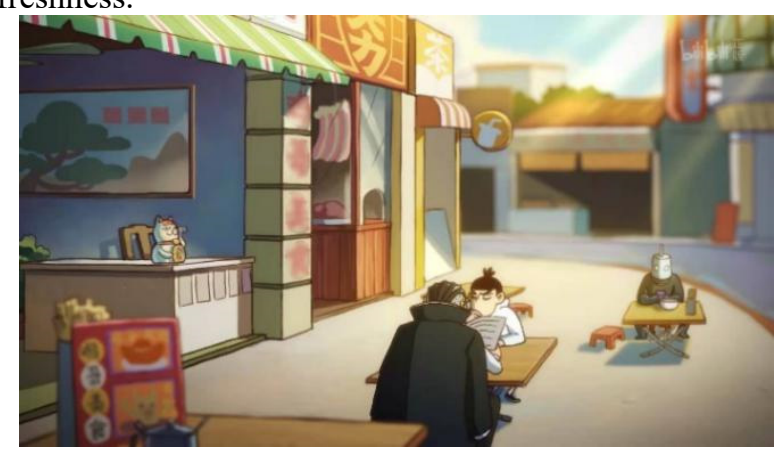

Fig3. Localized street life in the film

\subsection{Extract the characteristics of the local to create a curious geographical environment.}

Guangzhou is located in the Pearl River Delta, where rivers criss-cross and alluvial islands form near the mouth of the sea. The small island in the animation also fully refers to the local Canton this kind of geographical characteristics. At the same time, Canton is located in the tropic of Cancer. the climate of Canton belongs to subtropical climate. Abundant rainfall and sufficient light make the region rich in vegetation, which are also reflected in the animation scene.

In terms of architectural environment design, Due to historical reasons, last century a large number of Cantonese migrants to overseas for business and work, after years ago a lots of overseas Chinese returned to their hometown after the success of the venture, most of them to reconstruction the former residence. Years of the overseas life experience and knowledge to make them design the former residence for reconstruction used the architectural style of overseas for reference, at the same time retain the building of Chinese traditional style, thus forming the architectural characteristics of Chinese and western style in Canton area. This special localized design can also be reflected in this animation works's sense designs.

Much more the film is also combined with local 
characteristics in building design reference to the local of Canton region nostalgia form of architecture and interior decoration, such as the traditional architectural style Potear gable, nostalgic color interior floor tile, roof waterproof thermal insulation, indoor broad-leaved green plants, bonsai, with red paper common on the wall of the content of pragmatic business (business couplet and more commonly associated with rich) Canton-style couplet, hair salon in the old lights around the border of the mirror, and so on. These are all environment designs with local characteristics, and such details set the localized style for the film.

\subsection{The localized diet to enhance the other sense of effects}

Cantonese diet famed world one reason is plenty of food resource, the other was it was the trade and business centre of south china, thus there have many kinds of delicious diets from other region and foreign, with the time pasting formed Canton localized diet style.

In the process of watching the film, in addition to the entertainment sense of martial arts fighting, the dietary elements in the film will always arouse curiosity and interest in watching the film. These dietary elements such as Seven's business of beef offal stalls (different from other places in GuangZhou offal stalls use scissors to cut, which is Seven's scissors as a unique weapon, is different from other martial arts used feature point), Chaoshan beef meatball, street sell porridge on the surface of the powder snacks stalls, those in guangzhou and the surrounding community life, very common food stalls, the design of these stalls for the street life of the film increased local flavor.

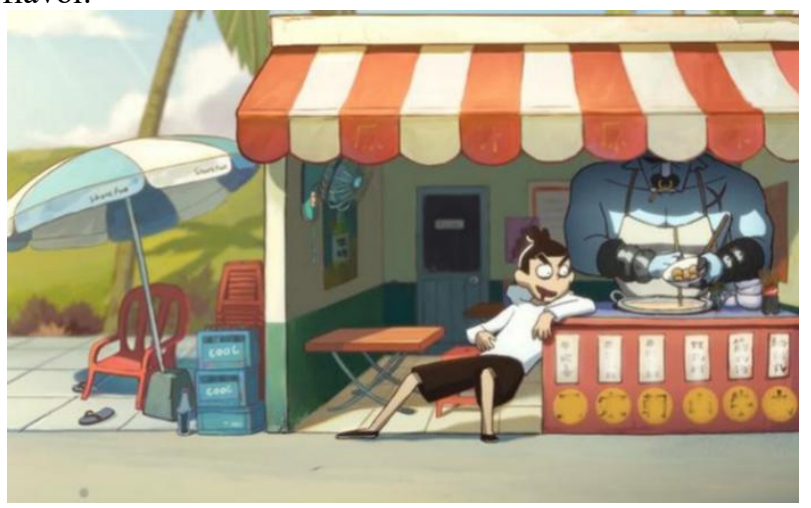

Fig4. Localized food stall in the film

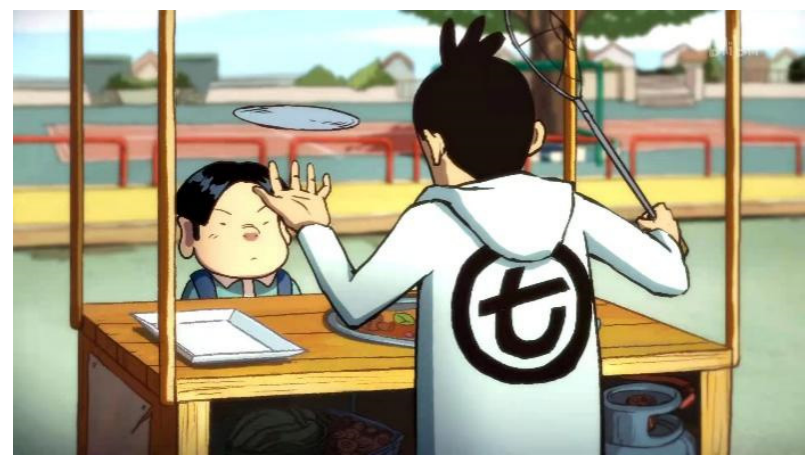

Fig5. Seven use scissors cut beef offal
Another food topic is about the eating culture of chickens in Canton. Chickens are very popular in Canton. The Cantonese use to saying "no chicken, no feast" refers to chickens. Chickens are re-organized locally (according to the growth time and the region, they are divided into different categories. Qingyuan chicken, Yangshan chicken, Zhanjiang chicken, etc.), how to eat more lick (cooking methods have steamed, boiled, salt baked, soya sauce, roast chicken, soup, hand to tear, etc.), the character of this films about chicken took four (Xiaojiji, Jidabao, Dafei and Shanji wang), and in the first quarter chicken in three sets of Dafei and the Shanji wang the story of the duel, (this story and Hollywood cartoon Ferdinand on 2018 has a similar plot setting.) Compared with the analogous plot design of international commercial animation, this film provides the international audience with similar topics about the localization of animals and humans in the existing plot of animation. In this aspect, the design is a manifestation of the international vision of this film.

These localized diet characteristics and diet habits are designed to increase the immersive experience for local audiences, and to increase the freshness and curiosity experience for non-local audiences (such as why the delicious hand-beaten ChaoShan beef meatball however without beef in it).

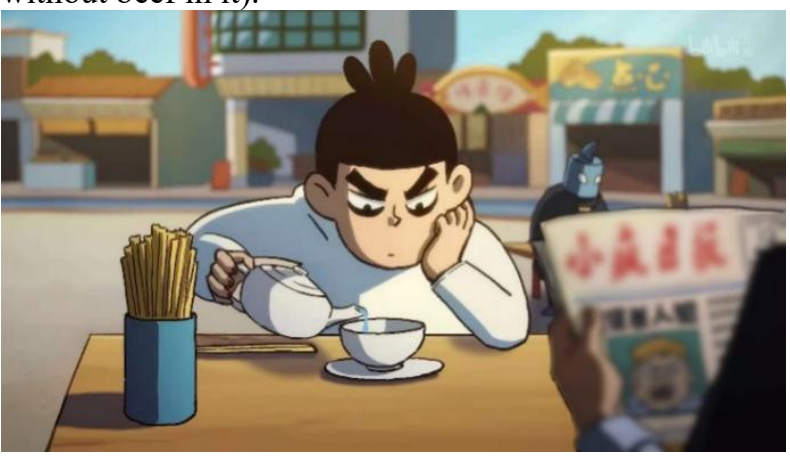

Fig6. localized diet habit in the film

\subsection{The funny lines and music design of Mou Lei tau (2)are full of Cantonese humor}

The blending and switching of Mandarin and Cantonese dialects and the lines and dialogues full of Cantonese humor make the film unique in language entertainment. Cantonese dubbing is mostly used in local films in Canton and Hong kong. Due to the limited coverage of dialect, the dubbing design is mainly composed of Mandarin mixed with Cantonese and Cantonese style Mandarin, forming various humorous and entertaining effects.

The Mou Lei Tau culture originally originated from the sub-culture of Hong Kong. Later, due to the development and spread of film and television entertainment, it gradually becomes a popular culture, which is often seen in Hong Kong films and performances of "stand-up comedy"(in Cantonese is Dung dug siu ) programs and Hong Kong film, such as Stephen Chow's films "Tang Pakfu Points Chou-heung", "Shao Lin soccer" and "King of comedy". In Mo Lei Tau humor, unexpected elements are combined by means of harmony, analogy, juxtaposing and imitation to produce extreme contrast which seems reasonable and unexpected or seems unreasonable but 
actually makes sense, forming the effect of humor and irony. For example, in the film about the character Xiaojiji's joke design: such as "Fast little flying chicken (the same pronunciation in chinese with plane and flying chicken)"; "In-ear flying chicken (headphones, aircraft plus headphones)", "muscle chicken (muscle male plus the chicken head)", these nouns can't be some things in real life, in the animation design by nouns plus images show will produce very abrupt visual experience, but these things are in the design of the story is totally reasonable, all these funny design makes the audience get the humor of something new and fresh and increase entertainment effect.

\subsection{Subversive music design, make audience feel refreshing}

In terms of the soundtrack and music design, this film also use the absurd reversal and contrast to improve the entertainment effect. There are soothing ballads with lyrics tampered by Wang Feng, for example, and a roughand-tumble metallic-rock soundtrack. The contrast between rock and folk music enhances the movie's entertainment.

In the plot design, the scriptwriters often use change and contrast to promote the development of the plot, to enhance the entertainment effect.

The most typical and entertaining soundtrack in the film is about Ah Jane in love with Ah Qiang."Ah Jane falls in love with Ah Qiang" is the work of Canton native band "Wu Tiao Ren", and the lyrics themselves are also designed with local characteristics. First of all, Jane and Ah Qiang are common local characteristics male and female names in Canton ;Secondly, the lyrics are designed with contrasting effects. For example, the first line "Ah Jane falls in love with Ah Qiang" is simple and straightforward. The second sentence, "On a night with stars" -- fantasy and beauty (first change); The third sentence, "Airplanes fly overhead" -- everyday and uneventful; "Meteors streak across the night sky" -- a fantasizing and expectant scene (second change); And then "though life is meaningless" -- realistic and cruel;" But love does make life more beautiful" -- Spiritual Sublimation (the third change brings the work to its climax)

In close body contact is originally appeared in the process of fighting in Martial arts film, most of the movie plot is commonly used in design but in this film, interject with Canton modern local custom folk rock style, coupled with the folk song lyrics is Mau Lei Tau type, mixed community and the feeling of modern poetry, inversion of high frequency strong contrast effects and audio-visual effects, makes the plot of the comedy effect is improved, even so that the additional effects increased the song "Ah Jane fell in love with Ah Qiang" in the spread of network and popular.

The other worth mention music design is the film's ending MV design. In the MV all the scene of the island can be seen, such as the road along the sea, palm trees, the sunlight shine on the sea, people playing at the sand and so on. Seven ride a red motorcycle on the road to dating the girl who fight with in the film. All of these design make the character of animation came in local day life with the soft slowly background music and beautiful lyrics to hart, make audience feel a unusual audio-visual experience.

Except these director design the whole music of the film use difference style at the begin, the middle and the end, make them form the strong contrast and increase the film's entertainment effects. This design make the audience experience the a roller coaster of emotions during the movie watching.

\section{Conclusion}

From ordinary people day life and local culture is plain and normal, but these things are the resource of animation creation. Only based on the local living environment, the film explores the local advantages and characteristics to create, and the affinity of the audio-visual feeling of the work will be prominent, in order to make an infectious, fleshly and energetic animation work. In the current context of globalization, it is a good direction for the development of domestic animation and an experience worthy of promotion to highlight individuality and reflect local characteristics and culture, Works with clear features and differentiated expression, can gain the recognition of local audiences and the curiosity of audiences in other regions of the world and enhance the difference culture exchange.

\section{Notes:}

1. Fanju is a term originating from serial animation or TV series in Japan. Nowadays, it refers to the serial animation or live action series designed and produced by Fanju and broadcast on various media platforms

2. Mau Lei Tau originally means "no reason things", which is Cantonese slang in the South China of Canton province. It means Unable to distinguish between head and tail, no reason, no logic, and confusion. Mau Lei Tau culture was originally a sub-culture bred in Hong Kong, but later evolved into entertainment pop culture due to the application and dissemination of film and television works "Stand-up comedy", or "Dung dug siu", is a cantonese stand-up comedian introduced and invented by Hong Kong actor Wong ZiHua and Mau Lei Tau plots and dialogue are often seen in Stephen Chow's films.

\section{ACKNOWLEDGMENTS}

In the process of writing this paper, I got the help and supports from Guangzhou Academy of Fine Arts' Professor Chen Zhanwei and Director He Weifeng. Professor Chen ever was Director He's advisor of college. I should appreciate for he's introduce made me could to gain most first resources of the work from director. I also should appreciate director $\mathrm{He}$ answer many questions about the work's each aspects in his busy working time. I would like to express my appreciate to their enthusiastic help and supports. 


\section{REFERENCES}

1. Rayns, Tony (2010). "Ozu Yasujiro, tofu maker". Archived from the original on 3 August 2012. Retrieved 19 February 2019

2. Zheng, Jenny (14 January 2020). "Netflix's 'Scissor Seven' is a hilarious, genre-hopping animated series". Daily Dot. Retrieved 17 January 2020.

3. Netflix - Scissor Seven". Retrieved 17 January 2020.

4. LionBridge 4 January 2020 "Localization Globalization Internationalization-Whats the difference"

https://www.lionbridge.com/blog/translationlocalizat ion/localization-globalization-internationalizationwhats-the-difference

5. Laura Turner Garrison" Looking at Hong Kong Humor" Sept. 21, 2011

https:/www.vulture.com/amp/2011/09/looking-athong-kong-humor.html

6. Mo Lei Tau https://de.academic.ru/dic.nsf/dewiki/967233

7. Hale, Mike (5 October 2014). "Lightning Fast With His Feet and His Jokes". The New York Times. ISSN 0362-4331. Retrieved 6 March 2020.”"Directors' 10 Greatest Films of All Time". Sight \& Sound. British Film Institute. 4 December 2014.

9. Hsiung, Deh-Ta. Simonds, Nina. Lowe, Jason. [2005] (2005). The food of China: a journey for food lovers. Bay Books. ISBN 978-0-681-02584-4. p17.

10. Civitello, Linda (2011-03-23). Cuisine and Culture: A History of Food and People. p. 281. ISBN 9781118098752.

11. Wordie, Jason (2002). Streets: Exploring Hong Kong Island. Hong Kong: Hong Kong University Press. ISBN 962-209-563-1. 